\title{
Glutamate Spillover Modulates GABAergic Synaptic Transmission in the Rat Midbrain Periaqueductal Grey via Metabotropic Glutamate Receptors and Endocannabinoid Signaling
}

\author{
Geoffrey M. Drew, Vanessa A. Mitchell, and Christopher W. Vaughan \\ Pain Management Research Institute, Kolling Institute of Medical Research, Northern Clinical School, The University of Sydney at Royal North Shore \\ Hospital, St. Leonards, New South Wales 2065, Australia
}

\begin{abstract}
Glutamate spillover regulates GABAergic synaptic transmission at several CNS synapses via presynaptic ionotropic and metabotropic glutamate receptors (mGluRs). We have previously demonstrated that activation of group I-III mGluRs inhibits GABAergic transmission in the midbrain periaqueductal gray (PAG), a region involved in organizing behavioral responses to threat, stress, and pain. Here, we examined the role of glutamate spillover in the modulation of GABAergic transmission in the PAG. Using whole-cell recordings from rat PAG slices, we found that evoked IPSCs were reduced by the nonspecific glutamate transport blockers DL-threo- $\beta$-benzyloxyaspartic acid (TBOA) and L-trans-pyrrolidine-2,4-dicarboxylic acid, but not by the glial GLT1-specific blocker dihydrokainate. In contrast, TBOA had no effect on evoked IPSCs when glutamate uptake into the postsynaptic neuron was selectively impaired. TBOA increased the pairedpulse ratio of evoked IPSCs and reduced the rate but not the amplitude of spontaneous miniature IPSCs. The effect of TBOA on evoked IPSCs was abolished by the broad-spectrum mGluR antagonist (2S)-2-amino-2-[(1S,2S)-2-carboxycycloprop-1-yl]-3-(xanth-9-yl) propanoic acid $(100 \mu \mathrm{M})$, reduced by the mGluR5-specific antagonist 2-methyl-6-(phenylethynyl)pyridine hydrochloride (MPEP) and mimicked by the mGluR1/5 agonist (RS)-3,5-dihydroxyphenylglycine (DHPG). Furthermore, the effects of both TBOA and DHPG were reduced by the cannabinoid CB1 receptor antagonist 1-(2,4-dichlorophenyl)-5-(4-iodophenyl)-4-methyl- $N$-1-piperidinyl-1 $H$-pyrazole-3carboxamide (AM251). Finally, although MPEP and AM251 had no effect on single evoked IPSCs, they increased evoked IPSCs during repetitive stimulation. These results indicate that neuronal glutamate transporters limit mGluR5 activation and endocannabinoid signaling, but may be overwhelmed during conditions of elevated glutamate release. Thus, neuronal glutamate transporters play a key role in regulating endocannabinoid-mediated cross talk between glutamatergic and GABAergic synapses within the PAG.
\end{abstract}

Key words: glutamate transporters; metabotropic glutamate receptor; GABA; cannabinoid; periaqueductal grey; analgesia

\section{Introduction}

Rapid clearance of glutamate from the synaptic cleft is critical for preventing excitotoxicity and for maintaining signal specificity of excitatory synaptic transmission. Glutamate uptake at central synapses is mediated by plasma membrane-bound transporters located on neighboring neurons and glia. Five human glutamate transporter isoforms have been cloned to date, EAAT1 (GLAST), EAAT2 (GLT1), EAAT3 (EAAC1), EAAT4, and EAAT5. In rodents, GLAST and GLT1 are expressed primarily in glial cells, are distributed throughout the CNS, and together are responsible for the bulk of glutamate uptake at most synapses (Bergles et al., 1999; Danbolt, 2001). EAAC1, in contrast, is thought to be the

\footnotetext{
Received May 25, 2007; revised Nov. 28, 2007; accepted Dec. 1, 2007.

This work was supported by Australian National Health and Medical Research Council Grant 457563 (C.W.V.) and a CJ Martin Overseas Biomedical Fellowship 402868 (G.M.D.).

Correspondence should be addressed to Dr. Geoffrey M. Drew, Pain Management Research Institute, Northern Clinical School, Royal North Shore Hospital, St. Leonards, New South Wales 2065, Australia. E-mail: gdrew@med.usyd.edu.au.

DOI:10.1523/JNEUROSCI.4876-07.2008

Copyright $\odot 2008$ Society for Neuroscience $\quad$ 0270-6474/08/280808-08\$15.00/0
}

major neuronal transporter in most regions of the CNS, although its specific contribution to glutamate clearance and synaptic function remains unclear (Nieoullon et al., 2006). EAAT4 and EAAT5 are restricted largely to the cerebellar cortex and retina, respectively (Danbolt, 2001).

Electrophysiological studies have shown that pharmacological blockade of glutamate uptake results in glutamate spillover, activation of extrasynaptic glutamate receptors, and alterations in glutamatergic synaptic transmission [for review, see Diamond (2002) and Huang and Bergles (2004)]. A number of studies have also demonstrated that inhibition of glutamate transporters induces spillover and modulation of GABAergic synaptic transmission via activation of NMDA, kainate, and metabotropic glutamate receptors (mGluRs) on GABAergic terminals within the cerebellum, hippocampus, supraoptic nucleus, and nucleus tractus solitarii (Fitzsimonds and Dichter, 1996; Mitchell and Silver, 2000; Semyanov and Kullmann, 2000; Jiang et al., 2001; Piet et al., 2003; Huang and Bordey, 2004).

The midbrain periaqueductal gray (PAG) plays a pivotal role in integrating an animal's somatomotor, autonomic, and behav- 
ioral responses to threat, stress, and pain, and is a major site of the analgesic actions of $\mu$-opioids and cannabinoids (Keay and Bandler, 2001; Fields et al., 2006). Opioids and cannabinoids are thought to produce analgesia from within the PAG by reducing GABAergic inhibition of output neurons that form part of a descending analgesic pathway (Fields et al., 2006). We have previously shown that, like opioids and cannabinoids, group I, II, and III mGluR agonists inhibit GABAergic transmission within the PAG via a presynaptic mechanism (Vaughan and Christie, 1997; Vaughan et al., 2000; Drew and Vaughan, 2004). However, it is not clear whether or under what conditions these receptors are activated by endogenously released glutamate in the PAG. The PAG expresses the glutamate transporters EAAC1 and GLT1, but not GLAST (Rothstein et al., 1994; Schindler et al., 1998; Barbaresi, 2001). Here, we investigated the role of glutamate transporters in regulating GABAergic synaptic transmission in PAG slices. We found that inhibition of a postsynaptic glutamate transporter, presumably EAAC1, suppresses GABAergic transmission onto that neuron via activation of mGluR5 and presynaptic cannabinoid $\mathrm{CB}_{1}$ receptors. Thus, by competing with mGluR5 for ambient glutamate, neuronal glutamate transporters limit inhibitory endocannabinoid-mediated cross talk between glutamatergic and GABAergic synapses and are likely to play an important role in the analgesic and anxiolytic functions of the PAG.

\section{Materials and Methods}

Slice preparation. Male and female Sprague Dawley rats (16- to 24-d-old) were deeply anesthetized with halothane and decapitated, in accordance with protocols approved by the institutional Animal Care and Ethics Committee. Transverse or horizontal midbrain slices $(300-350 \mu \mathrm{m})$ containing PAG were cut using a vibratome (VT1000S; Leica Microsystems, Nussbloch, Germany) in ice-cold artificial CSF (ACSF), as described previously (Drew and Vaughan, 2004). The slices were maintained at $34^{\circ} \mathrm{C}$ in a submerged chamber containing ACSF equilibrated with $95 \% \mathrm{O}_{2}$ and $5 \% \mathrm{CO}_{2}$. The slices were then individually transferred to a chamber and superfused continuously (1.4-1.6 $\mathrm{ml} / \mathrm{min}$ ) with ACSF (at $34^{\circ} \mathrm{C}$ unless otherwise stated) of the following composition (in $\mathrm{mm}$ ): $126 \mathrm{NaCl}, 2.5 \mathrm{KCl}, 1.4 \mathrm{NaH}_{2} \mathrm{PO}_{4}, 1.2 \mathrm{MgCl}_{2}, 2.4 \mathrm{CaCl}_{2}, 11$ glucose, and $25 \mathrm{NaHCO}_{3}$.

Electrophysiology. PAG neurons were visualized using infrared Nomarski or Dodt contrast gradient optics on an upright microscope (BX51; Olympus, Tokyo, Japan). Whole-cell voltage-clamp recordings at -70 $\mathrm{mV}$ were made using an Axopatch 200B (Molecular Devices, Sunnyvale, CA) with an internal solution containing the following (in mM): 140 CsCl, 10 EGTA, 5 HEPES, $2 \mathrm{CaCl}_{2}, 2$ MgATP, and 3 QX-314 (pH 7.3; osmolarity, 270-290 mOsm/L). In experiments using Tris ${ }^{+}$-based internal solution, $\mathrm{CsCl}$ and $\mathrm{MgATP}$ were replaced with Tris $\mathrm{Cl}$ and TrisATP, respectively. In these experiments, recordings were started a minimum of $20 \mathrm{~min}$ after obtaining whole-cell mode. Series resistance $(<20 \mathrm{M} \Omega)$ was compensated by $80 \%$ and continuously monitored during experiments. Liquid junction potentials of $-4 \mathrm{mV}$ were corrected. Electrically evoked IPSCs were elicited in neurons via bipolar tungsten stimulating electrodes (tip separation, $100 \mu \mathrm{m}$ ) placed $50-200 \mu \mathrm{m}$ from the recording electrode (rate, $0.083 \mathrm{~s}^{-1}$; stimuli: $1-50 \mathrm{~V}, 20-400 \mu \mathrm{s}$ ), in the presence of the non-NMDA glutamate receptor antagonist 6-cyano-7nitroquinoxaline-2,3-dione disodium (CNQX) $(5 \mu \mathrm{M})$ and the glycine receptor antagonist strychnine $(5 \mu \mathrm{M})$. In other experiments, spontaneous miniature IPSCs were recorded in the presence of CNQX, strychnine, and tetrodotoxin (300 nM). Evoked and miniature IPSCs were abolished by the $\mathrm{GABA}_{\mathrm{A}}$ receptor antagonist SR95531 (10 $\mu \mathrm{M}, n=5$ each $)$.

IPSCs were filtered (1-2 kHz low-pass filter) and sampled $(5-10 \mathrm{kHz})$ for on-line and later off-line analysis (Axograph X; Axograph Scientific Software, Sydney, Australia). Miniature IPSCs were sampled in $5 \mathrm{~s} \mathrm{ep-}$ ochs every $6 \mathrm{~s}$ for analysis, and IPSCs above a preset threshold (4.5-5.5 SDs above baseline noise) were automatically detected by a sliding template algorithm, then manually checked off-line. All numerical data are
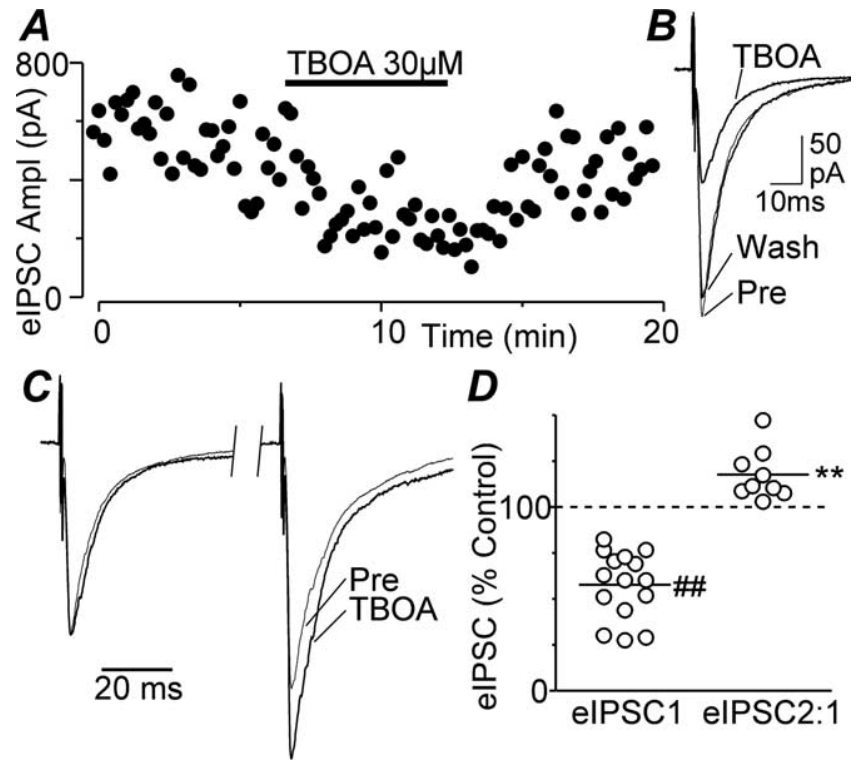

Figure 1. The glutamate transport blocker TBOA inhibits evoked IPSCS. $\boldsymbol{A}$, Time course of evoked IPSC (elPSC) amplitude (Ampl) during application of TBOA $(30 \mu \mathrm{M})$. $\boldsymbol{B}$, Averaged traces of evoked IPSC s before (Pre), during, and after (Wash) application of TBOA.C, Averaged traces in response to identical paired stimuli (IPSC 1-2 interval, $70 \mathrm{~ms}$ ) with IPSC1 normalized (left) before and during superfusion of TBOA. D, Scatter plot of the evoked IPSC amplitude (eIPSC1) and the ratio of evoked IPSC2:1 amplitudes (eIPSC2:1) in the presence of TBOA, expressed as a percentage of the pre-TBOA level. The lines represent the mean values. ${ }^{* *} p<0.01$; ${ }^{\# \#} p<$ 0.0001 . $A-C$ are taken from one neuron.

expressed as mean \pm SEM. Statistical comparisons of drug effects were made using paired Student's $t$ test, and comparisons between treatment groups were made with a one-way ANOVA using Dunnett's correction for post hoc comparisons. Differences were considered significant if $p<$ 0.05 .

Drug solutions. CNQX and strychnine hydrochloride were obtained from Sigma (Sydney, Australia); 1-(2,4-dichlorophenyl)-5-(4iodophenyl)-4-methyl- $N$ - 1-piperidinyl- $1 H$-pyrazole-3-carboxamide (AM251) from Cayman Chemicals (Ann Arbor, MI); L-(+)-2-amino-4phosphonobutyric acid (L-AP4), DL-2-amino-5-phosphonovaleric acid (DLAP5), 7-(hydroxyimino)-cyclopropa[b]chromen-1a-carboxylate ethyl ester (CPCCOEt), (2S, $\left.2^{\prime} R, 3^{\prime} R\right)-2-\left(2^{\prime}, 3^{\prime}\right.$-dicarboxycyclopropyl)glycine (DCGIV), (RS)-3,5-dihydroxyphenylglycine (DHPG), (2S,3S,4R)-2-carboxy-4isopropyl-3-pyrrolidineacetic acid [dihydrokainic acid (DHK)], SR95531 hydrobromide, (2S)-2-amino-2-[(1S,2S)-2-carboxycycloprop-1-yl]-3-(xanth9-yl) propanoic acid (LY341495), 2-methyl-6-(phenylethynyl)pyridine hydrochloride (MPEP), L-trans-pyrrolidine-2,4-dicarboxylic acid (1-PDC), (RS)- $\alpha$ methylserine- $O$-phosphate (MSOP), and DL-threo- $\beta$-benzyloxyaspartic acid (TBOA) from Tocris Bioscience (Bristol, UK); and QX-314 bromide and tetrodotoxin (TTX) from Alomone Labs (Jerusalem, Israel). Stock solutions of all drugs were made in distilled water, except LY341495 (in $1 \mathrm{~N} \mathrm{NaOH}$ ) and AM251 and TBOA (in dimethylsulfoxide), then diluted to working concentrations using ACSF immediately before use and applied by superfusion.

\section{Results}

Blocking glutamate transport inhibits GABAergic transmission via a presynaptic mechanism

Superfusion of the nontransportable neuronal and glial glutamate transport blocker TBOA $(30 \mu \mathrm{M})$ produced a reversible reduction in the amplitude of electrically evoked IPSCs in all lateral and ventrolateral PAG neurons tested (Fig. $1 A, B)(n=7$, 8 , respectively). On average, TBOA reduced the amplitude of evoked IPSCs to $58 \pm 5 \%$ of control (Fig. $1 D)(p<0.0001, n=$ 15). TBOA had no effect on the membrane current or the conductance of the neurons at $-70 \mathrm{mV}$. In some of these neurons, 

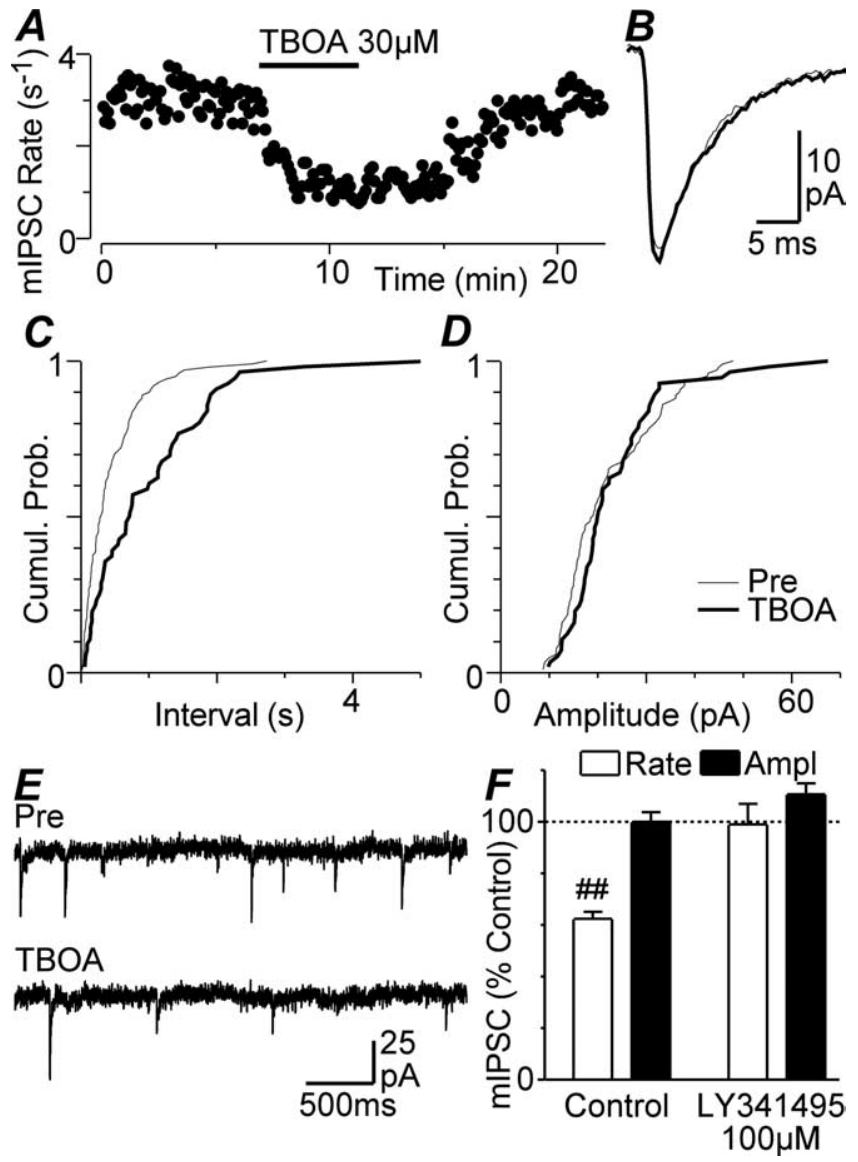

Figure 2. TBOA decreases the frequency of spontaneous miniature IPSCS. A, Time course of spontaneous miniature IPSC (mIPSC) rate during superfusion of TBOA (30 $\mu \mathrm{M})$. B, Averaged traces of miniature IPSCs before and during TBOA. C, D, Cumulative probability (Cumul. Prob.) distribution plots of miniature IPSC versus interevent interval $(\boldsymbol{C})$ and amplitude before (Pre) and during TBOA (D). $\boldsymbol{E}$, Representative raw traces before and during application of TBOA. $\boldsymbol{F}, \mathrm{Bar}$ chart of the mean rate and amplitude (Ampl) of miniature IPSCs in the presence of TBOA, expressed as a percentage of the predrug level in untreated neurons (control) and in neurons preincubated in LY341495 $(100 \mu \mathrm{m}) .{ }^{\# \#} p<0.0001$. A-E are taken from one neuron.

paired evoked IPSCs were elicited by two stimuli of identical strength in close succession (interstimulus interval, $70 \mathrm{~ms}$ ) (Fig. 1C). Under control conditions, the mean ratio of the amplitude of the paired evoked IPSCs was $1.26 \pm 0.11$, with both pairedpulse depression and facilitation being observed (evoked IPSC2/ IPSC1 ratio, $0.89-1.85 ; n=9)$. Superfusion of TBOA $(30 \mu \mathrm{M})$ increased the mean paired-pulse ratio to $1.51 \pm 0.13$ (Fig. $1 D$ ) $(p=0.009)$.

Superfusion of TBOA $(30 \mu \mathrm{M})$ also produced a reversible reduction in the rate of spontaneous miniature IPSCs in all PAG neurons tested (Fig. $2 A, E)(n=8)$. This reduction in rate was associated with a rightward shift in their cumulative interevent interval distributions (Fig. 2C). In contrast, TBOA had no effect on the amplitude and kinetics of miniature IPSCs, or on their cumulative amplitude distributions (Fig. $2 B, D$ ). On average, the mean rate and amplitude of miniature IPSCs in the presence of TBOA was $62 \pm 3 \%(p<0.0001)$ and $100 \pm 4 \%$ of control $(p=$ 0.9 ), respectively (Fig. $2 F$ ). Together with the observed increase in evoked IPSC paired-pulse ratio, this suggests that the inhibitory effect of TBOA on GABAergic transmission in PAG neurons is attributable to a decreased probability of transmitter release from presynaptic terminals.
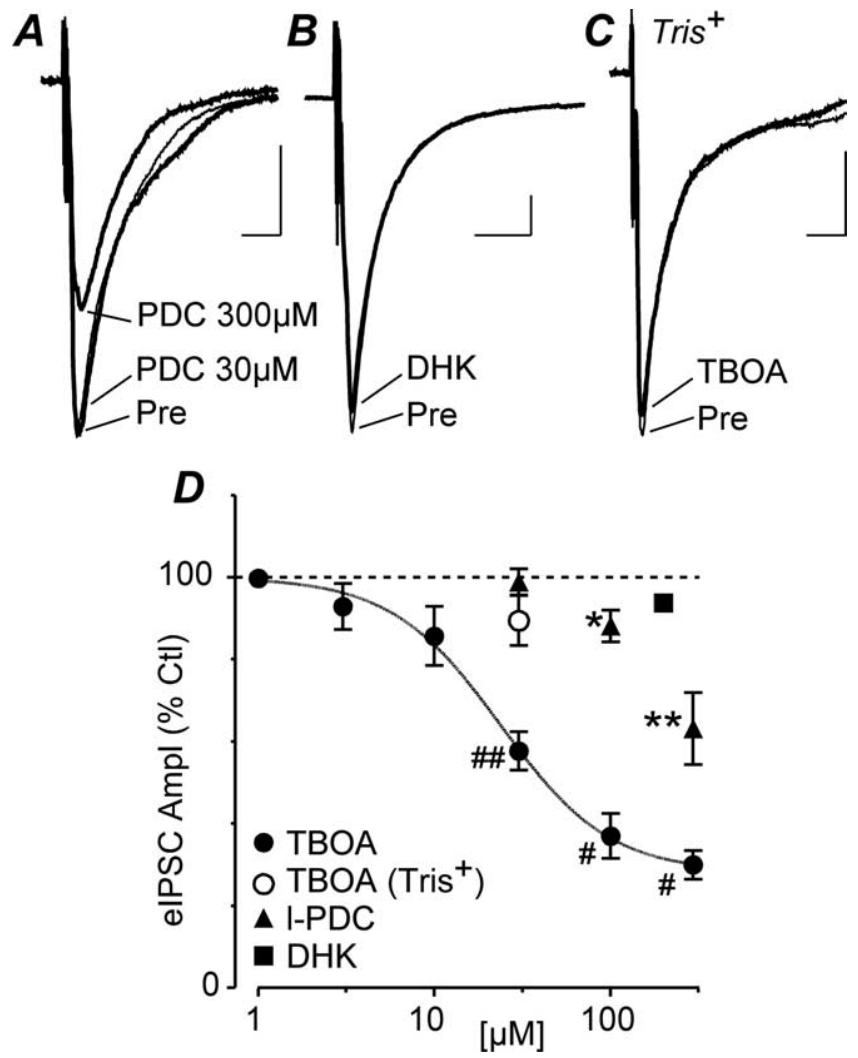

Figure 3. TBOA-induced inhibition of evoked IPSCs is mediated by a postsynaptic EAAC1-like transporter. $A, B$, Averaged traces of evoked IPSCS (eIPSCS) before (Pre) and during application of I-PDC (PDC, 30, $300 \mu \mathrm{m} ; \boldsymbol{A})$ and DHK (200 $\mu \mathrm{m} ; \boldsymbol{B})$. C, Averaged traces of evoked IPSCs before and during TBOA (30 $\mu \mathrm{M})$ in a neuron in which cations were replaced with $\mathrm{Tris}^{+}$in the recording pipette. $\boldsymbol{D}$, Concentration-response curves of the mean effect of TBOA (using normal and Tris +-based recording solutions), I-PDC, and DHK on evoked IPSCs, with all values expressed as a percentage of the predrug level (Ctl). ${ }^{*} p<0.05 ;{ }^{* *} p<0.01 ; "{ }^{\#} p<0.001 ;{ }^{\# \#} p<0.0001$. Ampl, Amplitude. $\boldsymbol{A}-\boldsymbol{C}$ are taken from different neurons. Calibration: 200 pA, $10 \mathrm{~ms}$.

TBOA-induced inhibition of evoked IPSCs is mediated by a postsynaptic transporter

We next examined which neuronal and/or glial glutamate transporter subtype(s) mediated the inhibitory effect of TBOA on evoked IPSCs. The TBOA-induced inhibition of evoked IPSCs was concentration dependent, with an $\mathrm{IC}_{50}$ of $25 \mu \mathrm{M}(95 \%$ confidence interval, $15-41 \mu \mathrm{M}$ ) and a slope factor of $1.4 \pm 0.5$ (Fig. $3 D$ ). The neuronal and glial glutamate transport blocker l-PDC produced a significant reduction in evoked IPSC amplitude at concentrations of 100 and $300 \mu \mathrm{M}(p=0.03$ and 0.01 , respectively, $n=5)$, but not at $30 \mu \mathrm{M}$ (Fig. $3 A, D)(p=0.8, n=5)$. In contrast, the GLT1-specific glial glutamate transport blocker DHK $(200 \mu \mathrm{M})$ had no significant effect on evoked IPSC amplitude (Fig. $3 B, D)(p=0.2, n=5)$.

This pharmacological profile is largely consistent with uptake of glutamate being mediated by the neuronal transporter, EAAC1. To investigate the involvement of neuronal glutamate transporters located on the recorded cell, we substituted Tris ${ }^{+}$ for physiological cations in the recording pipette to disrupt cation-dependent transporter function (Brasnjo and Otis, 2001). Under these conditions, superfusion of TBOA $(30 \mu \mathrm{M})$ did not produce a significant reduction in evoked IPSC amplitude (Fig. $3 C, D)(p=0.2, n=7)$. Collectively, these results suggest that TBOA reduces GABAergic synaptic transmission in PAG neurons predominantly by blocking neuronal EAAC1 on the postsynaptic neuron receiving the GABAergic inputs. 

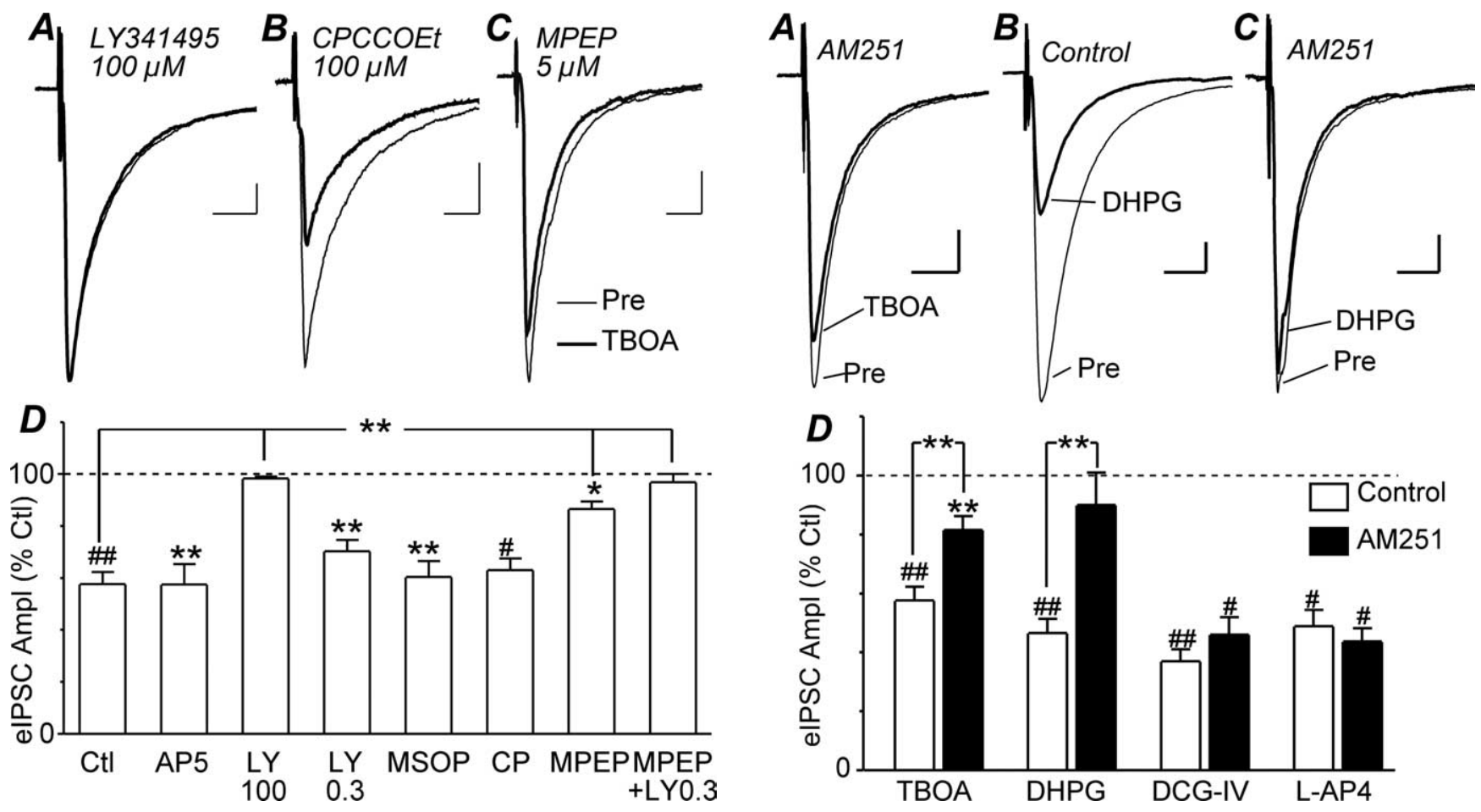

Figure 4. TBOA inhibits evoked IPSCs primarily through activation of mGluR5. A-C, Averaged traces of evoked IPSCs before (Pre) and during TBOA (30 $\mu \mathrm{M})$ in neurons preincubated in LY341495 (100 $\mu \mathrm{m} ; \boldsymbol{A})$, CPCCOEt (100 $\mu \mathrm{m} ; \boldsymbol{B})$ and MPEP $(5 \mu \mathrm{m} ; \boldsymbol{C})$. D, Bar chart of the mean amplitude (Ampl) of evoked IPSCs in the presence of TBOA, expressed as a percentage of the predrug level (Ctl), in neurons preincubated in AP5 $(25 \mu \mathrm{M}), \mathrm{LY} 341495$ (LY, 0.3 and $100 \mu \mathrm{M})$, CPCCOEt $(C P, 100 \mu \mathrm{M}), \operatorname{MPEP}(5-10 \mu \mathrm{M})$, and MSOP $(200 \mu \mathrm{M})$ compared with control neurons, which did not undergo preincubation (CtI). ${ }^{*} p<0.05 ;{ }^{* *} p<0.01$, ${ }^{\#} p<0.001 ;{ }^{\# \#} p<0.0001$. $A-C$ are taken from different neurons. Calibration: 200 pA, $10 \mathrm{~ms}$.

\section{Spillover-induced inhibition of GABAergic transmission is mediated via mGluR5}

TBOA may have reduced GABAergic transmission in PAG slices by enhancing glutamate spillover from the synaptic cleft onto extrasynaptic ionotropic, or metabotropic glutamate receptors. In the presence of the NMDA receptor antagonist AP5 $(25 \mu \mathrm{M})$, TBOA $(30 \mu \mathrm{M})$ produced a significant reduction in evoked IPSC amplitude ( $p=0.006, n=5)$, which was not significantly different from that produced by TBOA alone (Fig. $4 D)(p>0.05)$. However, in the presence of LY341495 (100 $\mu \mathrm{M})$, at a concentration that blocks all mGluR subtypes (Fitzjohn et al., 1998), TBOA $(30 \mu \mathrm{M})$ did not produce a significant reduction in evoked IPSC amplitude (Fig. $4 A, D)(p=0.1, n=5)$. Similarly, TBOA (30 $\mu \mathrm{M})$ did not produce a reduction in the rate of miniature IPSCs in the presence of LY341495 (100 $\mu \mathrm{M})$ (Fig. $2 F)(p=0.9, n=5)$.

TBOA $(30 \mu \mathrm{M})$ produced a significant reduction in evoked IPSC amplitude in the presence of LY341495 at a concentration that is selective for group II mGluRs ( $300 \mathrm{nM}, p=0.003, n=5$ ) and in the presence of the group III antagonist MSOP $(200 \mu \mathrm{M}$, $p=0.003, n=5)$, both of which were not significantly different from that produced by TBOA alone (Fig. $4 D)(p>0.05)$. Next, we tested the possible involvement of group I mGluRs. TBOA produced a significant reduction in evoked IPSC amplitude in the presence of the mGluR1-specific antagonist CPCCOEt $(100 \mu \mathrm{M})$ (Fig. $4 B, D)(p<0.0001, n=6)$ and the mGluR5-specific antagonist MPEP $(5-10 \mu \mathrm{M})($ Fig. $4 C, D)(p=0.003, n=9)$. However, the reduction in evoked IPSC amplitude produced by TBOA in the presence of MPEP $(p<0.01)$, but not CPCCOEt $(p>0.05)$, was significantly less than that produced by TBOA alone (Fig.

Figure 5. TBOA inhibits evoked IPSCs via cannabinoid $C_{1}$ receptor activation. $A-C$, Averaged traces of evoked IPSCS (elPSCs) before (Pre) and during TBOA (30 $\mu \mathrm{M})$ and DHPG $(10 \mu \mathrm{M})$ in neurons that were or were not preincubated in AM251 $(3 \mu \mathrm{M})$. $\boldsymbol{D}$, Bar chart of the mean amplitude (Ampl) of evoked IPSCs during application of TBOA (30 $\mu \mathrm{M})$, DHPG $(10 \mu \mathrm{M})$, DCG-IV $(1 \mu \mathrm{M})$, and L-AP4 $(10 \mu \mathrm{M})$, expressed as a percentage of the predrug level (CtI), in neurons that were preincubated in AM251 (3 $\mu \mathrm{M}$ ) or did not undergo preincubation (Control). ${ }^{* *} p<0.01$; ${ }^{\#} p<0.001 ;{ }^{\# \#} p<0.0001$. A-C are taken from different neurons. Calibration: $200 \mathrm{pA}, 10 \mathrm{~ms}$.

$4 D)$. Finally, TBOA $(30 \mu \mathrm{M})$ did not produce a significant reduction in evoked IPSC amplitude in the combined presence of $\operatorname{MPEP}(5 \mu \mathrm{M})$ and LY341495 (300 nM) (Fig. 4D) $(p=0.4, n=5)$. These observations indicate that the TBOA-induced inhibition of GABAergic synaptic transmission is largely mediated by activation of mGluR5 with a lesser contribution from group II mGluRs.

We also examined the effect of the group I agonist DHPG on evoked IPSCs. As observed previously, DHPG $(10 \mu \mathrm{M})$ produced a significant reduction in evoked IPSC amplitude (Fig. $5 B, D$ ) (inhibition $=47 \pm 5 \%, p<0.0001, n=9$ ). The DHPG induced inhibition was abolished by preincubation in MPEP $(5-10 \mu \mathrm{M}$, inhibition $=92 \pm 7 \%$ of control, $p=0.3, n=4)$, but not in CPCCOEt $(100 \mu \mathrm{M}$, inhibition $=54 \pm 9 \%$ of control, $p=0.008$, $n=5)$.

\section{TBOA and group I mGluR activation reduce GABAergic transmission via cannabinoid $\mathrm{CB}_{1}$ receptors}

It has been demonstrated in a number of brain regions that activation of group I mGluRs inhibits GABAergic synaptic transmission indirectly via the endocannabinoid system (Maejima et al., 2001; Varma et al., 2001; Ohno-Shosaku et al., 2002; Galante and Diana, 2004). We therefore examined whether the TBOAinduced inhibition of GABAergic transmission was also mediated via endocannabinoids within the PAG. TBOA $(30 \mu \mathrm{M})$ produced a significant reduction in the amplitude of evoked IPSCs in the presence of the cannabinoid $\mathrm{CB}_{1}$ receptor antagonist AM251 (3 $\mu \mathrm{M}, p=0.004, n=9)$; however, this was significantly less than in its absence (Fig. $5 A, D)(p<0.01)$.

We also examined the effect of AM251 ( $3 \mu \mathrm{M})$ on group I, II, and III mGluR agonist-induced inhibition of GABAergic trans- 


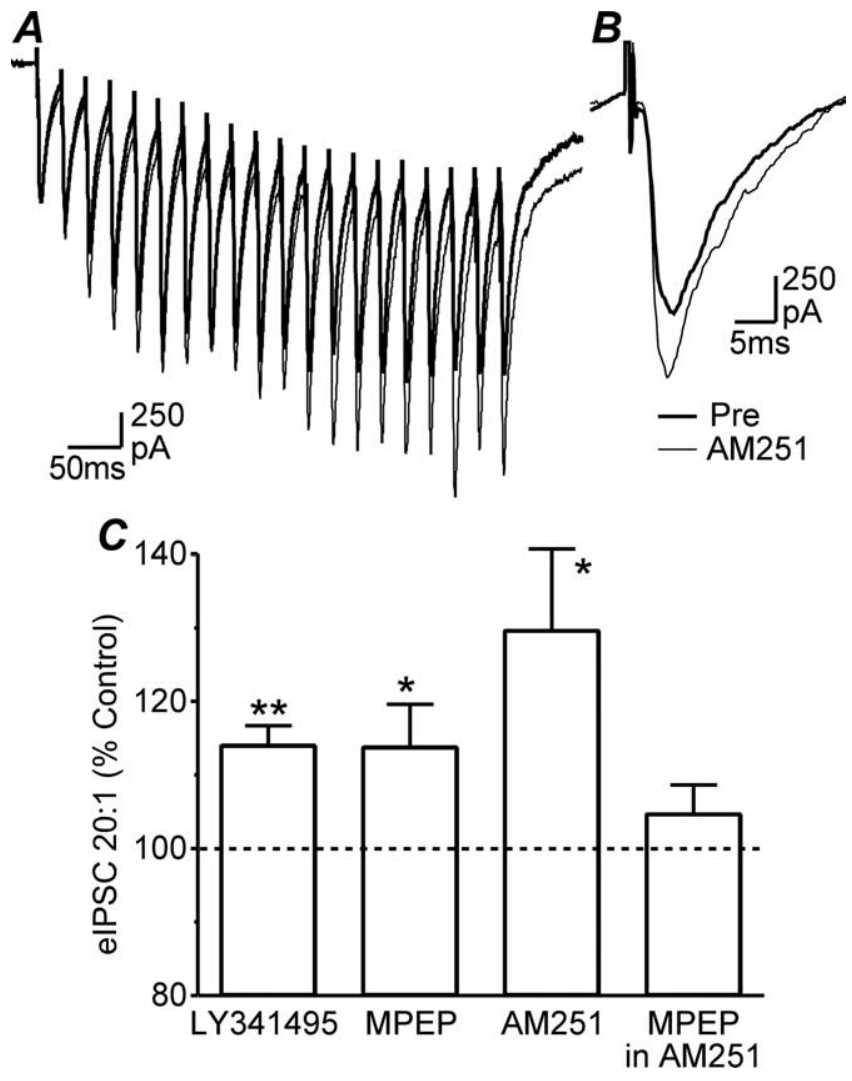

Figure 6. Activity-dependent endogenously produced cannabinoids inhibit evoked IPSCS. $\boldsymbol{A}$, Averaged traces of trains of 20 evoked IPSCs (eIPSCs) before (Pre) and during AM251 (3 $\mu \mathrm{m}$ ). $\boldsymbol{B}$, Averaged traces of the 20th evoked IPSC from $\boldsymbol{A}$ with the prestimulus baselines aligned to show facilitation by AM251 ( $3 \mu \mathrm{M})$. C, Bar chart of the amplitude of evoked IPSC20/1 in a train during application of LY341495 (100 $\mu \mathrm{M}), \operatorname{MPEP}(10 \mu \mathrm{M})$, and AM251 (3 $\mu \mathrm{M})$, expressed as a percentage of the predrug level, and during application of MPEP $(10 \mu \mathrm{M})$ in neurons preincubated in AM251 (3 $\mu \mathrm{M})$. $\boldsymbol{A}$ and $\boldsymbol{B}$ are from the same neuron. ${ }^{*} p<0.05 ;{ }^{* *} p<0.01$.

mission. The group I-selective agonist DHPG $(10 \mu \mathrm{M})$ produced a significant reduction in evoked IPSC amplitude in the absence $(p<0.0001, n=9)$ but not in the presence of AM251 (Fig. $5 B, C)$ $(p=0.4, n=6)$. The group II-selective agonist DCG-IV $(1 \mu \mathrm{M})$ produced a significant reduction in evoked IPSC amplitude in the absence $(p<0.0001, n=6)$ and presence of AM251 (Fig. 5D) ( $p=0.0003, n=6$ ). Similarly, the group III-selective agonist L-AP4 $(10 \mu \mathrm{M})$ produced a significant reduction in evoked IPSC amplitude in the absence ( $p=0.0008, n=5)$ and presence of AM251 (Fig. 5D) $(p=0.0002, n=5)$.

\section{Synaptically released glutamate inhibits GABAergic transmission}

The above experiments demonstrated that blockade of glutamate uptake leads to inhibition of GABAergic synaptic transmission. We next examined whether there was endogenous glutamatemediated inhibition of GABAergic synaptic transmission. Application of LY341495 $(100 \mu \mathrm{M})$ had no significant effect on the amplitude of evoked IPSCs (103 $\pm 5 \%$ of control, $p=0.6, n=6$ ). However, at room temperature, when rates of glutamate uptake are reduced, LY341495 $(100 \mu \mathrm{M})$ produced an increase in the amplitude of evoked IPSCs ( $120 \pm 6 \%$ of control, $p=0.03, n=5$ ).

We next examined whether activity-dependent glutamate release inhibits GABAergic synaptic transmission by examining prolonged trains of IPSCs evoked at $50 \mathrm{~Hz}$ (Fig. $6 \mathrm{~A}$ ). At $34^{\circ} \mathrm{C}$, both LY341495 $(100 \mu \mathrm{M})$ and MPEP $(10 \mu \mathrm{M})$ produced an in- crease in the amplitude of the 20th evoked IPSC in a train (Fig. $6 C)(p=0.001,0.04, n=8,6)$. A similar effect was observed with AM251 $(3 \mu \mathrm{M})$ (Fig. $6 A-C)(p=0.04, n=5)$. In contrast, in the presence of AM251 ( $3 \mu \mathrm{M})$, MPEP $(10 \mu \mathrm{M})$ had no effect on the amplitude of the 20th evoked IPSCs in a train (Fig. $6 C)(p=0.3$, $n=5$ ), implying that the activity-dependent activation of mGluR5 and CB1 receptors inhibited evoked IPSCs in the train via a common pathway.

\section{Discussion}

This study demonstrates that neuronal glutamate transporters limit heterosynaptic endocannabinoid-mediated cross talk between glutamatergic and GABAergic synapses within the midbrain PAG. This is mediated primarily through mGluR5-induced release of endocannabinoids, which activate presynaptic cannabinoid $\mathrm{CB}_{1}$ receptors. The regulation of endogenous glutamateinduced activation of mGluR5 by neuronal glutamate transporters is likely to play an important role in regulating the endocannabinoid-mediated analgesic functions of the PAG.

\section{Presynaptic inhibition of GABAergic transmission by glutamate spillover}

In the present study, the neuronal and glial glutamate transport blocker TBOA reversibly inhibited $\mathrm{GABA}_{\mathrm{A}}$ receptor-mediated synaptic transmission. This effect was likely to be produced via a presynaptic mechanism, because it was associated with an increase in the paired-pulse ratio evoked IPSCs and a reduction in the frequency but not the amplitude of spontaneous miniature IPSCs, as demonstrated previously for opioids and cannabinoids in the PAG (Vaughan and Christie, 1997; Vaughan et al., 2000). The lack of effect on miniature IPSC amplitude and kinetics also indicates that, under our experimental conditions, TBOA did not reduce GABAergic transmission via disruption of presynaptic glutamate transporter-mediated GABA synthesis, as has been demonstrated at other CNS synapses (Sepkuty et al., 2002; Mathews and Diamond, 2003).

The PAG expresses the glutamate transporters EAAC1 and to a lesser extent GLT1, but not GLAST (Rothstein et al., 1994; Schindler et al., 1998; Barbaresi, 2001). Several observations suggest that the effect of TBOA on GABAergic synaptic transmission was mediated by EAAC1. First, TBOA inhibited evoked IPSCs with an $\mathrm{IC}_{50}$ of $25 \mu \mathrm{M}$, whereas 1-PDC was effective only at concentrations of $100 \mu \mathrm{M}$ and above, which is more consistent with EAAC1, rather than GLT1, involvement (Arriza et al., 1994). Second, the glial GLT1-selective blocker dihydrokainate, at a concentration that inhibits evoked IPSCs in other brain slice preparations (Semyanov and Kullmann, 2000; Piet et al., 2003), had no effect on evoked IPSCs in our study. Finally, when postsynaptic cation-dependent transporter function was impaired by replacing physiological cations with Tris $^{+}$in the postsynaptic neuron (Brasnjo and Otis, 2001), the effect of TBOA was abolished. Together, these findings suggest that glutamate spillover was mediated by blockade of EAAC1 in the postsynaptic neuron. This is consistent with the finding that EAAC1 is expressed in the plasma membrane of neuronal soma and dendrites within the PAG (Schindler et al., 1998; Barbaresi, 2001). Nevertheless, we cannot discount the possibility that presynaptic EAAC1 plays a role in regulating GABAergic transmission under certain conditions, because it is also expressed in discrete populations of axon terminals forming symmetric synapses in the PAG (Barbaresi, 2001).

\section{Glutamate spillover-induced $\mathrm{mGluR}$ activation}

In a number of brain regions, glutamate transporters modulate GABAergic synaptic transmission by limiting heterosynaptic 
spillover of glutamate onto presynaptic group II/III mGluRs and ionotropic kainate and NMDA receptors (Fitzsimonds and Dichter, 1996; Semyanov and Kullmann, 2000; Jiang et al., 2001; Piet et al., 2003; Huang and Bordey, 2004). In the present study, the TBOA-induced inhibition of GABAergic transmission was likely to be mediated by metabotropic, rather than ionotropic, glutamate receptors. Thus, whereas the effects of TBOA were abolished by the broad-spectrum mGluR antagonist LY341495 $(100 \mu \mathrm{M})$, they were unaffected by the NMDA antagonist AP5, and all recordings were made in the presence of the AMPA/kainate antagonist CNQX.

In situ hybridization and immunohistochemical studies have demonstrated the presence of group I (mGluR1/5), group II (mGluR2/3), and group III (mGluR4/7) receptors within PAG (Ohishi et al., 1995; Azkue et al., 1997; Tamaru et al., 2001; de Novellis et al., 2003). Furthermore, we have previously shown that group I, II, and III mGluR activation inhibits GABAergic synaptic transmission in the PAG (Drew and Vaughan, 2004). In the present study, TBOA-induced inhibition of GABAergic transmission was largely mediated by mGluR5, because it was significantly reduced by the mGluR5-specific antagonist MPEP $(5-10 \mu \mathrm{M})$, but not by mGluR1 (100 $\mu \mathrm{M}$ CPCCOEt), group II (300 nM LY341495), or group III mGluRs (200 $\mu \mathrm{M}$ MSOP) antagonists. Like EAAC1, mGluR5 is predominantly expressed in soma and dendrites of PAG neurons (Azkue et al., 1997; de Novellis et al., 2003), which is similar to the postsynaptic distribution of group I mGluRs and EAAC1 in other brain regions. Indeed, at Purkinje cell synapses, inhibition of postsynaptic glutamate transporters dramatically alters the stimulus-response relationship for mGluR1-mediated EPSCs and enhances mGluR1-dependent synaptic plasticity (Brasnjo and Otis, 2001; Wadiche and Jahr, 2005). This suggests that perisynaptic neuronal transporters function to restrict glutamate availability at group I mGluRs and limit their activation.

The residual TBOA-induced inhibition observed in the presence of MPEP was abolished by addition of a selective group II mGluR antagonist, LY341495 (300 nM), implying that glutamate spillover onto mGluR2/3-containing GABAergic terminals also made a contribution. This is similar to the glutamate spillover onto presynaptic group II/III mGluRs on GABAergic terminals during inhibition of glutamate uptake described in other brain regions (Fitzsimonds and Dichter, 1996; Semyanov and Kullmann, 2000; Piet et al., 2003). The precise distribution of group II and III receptors within the PAG, however, has not been examined.

\section{Glutamate spillover drives endocannabinoid signaling}

Our results suggest that TBOA-induced glutamate spillover reduces GABAergic synaptic transmission via mGluR5-induced production of endocannabinoids, which act via presynaptic cannabinoid $\mathrm{CB}_{1}$ receptors. In the present study, the cannabinoid $\mathrm{CB}_{1}$ receptor antagonist AM251 greatly reduced the effect of TBOA and abolished the effect of the group I, but not group II and III, agonists on evoked IPSCs. It has previously been demonstrated that cannabinoid $\mathrm{CB}_{1}$ receptors are located on GABAergic nerve terminals and that $C_{1}$ receptor activation inhibits GABAergic synaptic transmission via a presynaptic mechanism within the PAG (Tsou et al., 1998; Vaughan et al., 2000). These observations indicate that the endocannabinoid-mediated actions on GABAergic transmission within PAG are likely to occur downstream from mGluR5 activation. In support of this, it has been shown that mGluR5 colocalizes with diacylglycerol lipase- $\alpha$, the synthetic enzyme of the endocannabinoid 2-arachidonoylglycerol (2-AG), in perisynaptic regions of striatal medium spiny neurons (Uchigashima et al., 2007). In addition, group I mGluR activation initiates 2-AG biosynthesis (Jung et al., 2005) and endocannabinoid-mediated synaptic plasticity in several other brain regions (Ohno-Shosaku et al., 2002; Zhu and Lovinger, 2005; Grueter et al., 2006; Centonze et al., 2007; Uchigashima et al., 2007). In the present study, we have not identified the endocannabinoid involved; however, anandamide and 2-AG are potential candidates, because they are both produced within the PAG under certain conditions (Walker et al., 1999; Hohmann et al., 2005).

In addition to pharmacological inhibition of glutamate uptake, the present study has demonstrated that mGluR5endocannabinoid inhibition of GABAergic synaptic transmission can be engaged under physiological conditions. In the cerebellum and hippocampus, it has been shown that activity-dependent release of glutamate can overcome uptake systems and lead to spillover-induced inhibition of GABAergic synaptic transmission via activation group II/III mGluRs (Mitchell and Silver, 2000; Semyanov and Kullmann, 2000). Furthermore, glutamate spillover inhibits glutamatergic transmission in the cerebellum via group I mGluR-induced endocannabinoid signaling (Marcaggi and Attwell, 2005; Wadiche and Jahr, 2005). In the present study, it was found that although mGluR5 (MPEP, $10 \mu \mathrm{M}$ ) and broadspectrum mGluR antagonists (LY341495, $100 \mu \mathrm{M}$ ) had no effect on single evoked IPSCs, they increased IPSCs evoked by repetitive stimulation at rates within the range of firing rates encountered in vitro (Sanchez and Ribas, 1991; Ogawa et al., 1994). Similarly, AM251 increased evoked IPSCs during repetitive stimulation and occluded any further increase in IPSCs during subsequent addition of MPEP. These findings indicate that activity-induced glutamate release can overcome uptake, leading to spilloverinduced endocannabinoid inhibition of GABAergic synaptic transmission within the PAG. It should be noted, however, that the increase in repetitive evoked IPSCs produced by AM251 was greater than that produced by LY341495 or MPEP. This suggests that activity-induced endocannabinoid inhibition might also be induced by mechanisms other than mGluR activation.

\section{Functional implications}

Modulation of the endocannabinoid system represents a promising new target for anxiety and chronic pain states (Kathuria et al., 2003; Costa et al., 2006; Jayamanne et al., 2006; La Rana et al., 2006). The PAG plays an essential role in cannabinoid modulation of analgesia and anxiety (Martin et al., 1995; Lichtman et al., 1996; Palazzo et al., 2001; Finn et al., 2003; Moreira et al., 2007). It has been shown that both noxious peripheral stimulation and psychological stressors can induce glutamate release and endocannabinoid production within the PAG and that endocannabinoids mediate a component of stress-induced analgesia within this brain structure (Walker et al., 1999; Silva et al., 2000; Hohmann et al., 2005). Like $\mu$-opioids, it is thought that cannabinoids produce analgesia from within the PAG by reducing GABAergic transmission onto neurons that form part of an endogenous descending analgesic system (Fields et al., 2006). The present results point to a possible mechanism for endocannabinoid-mediated analgesia within the PAG, whereby spillover of synaptically released glutamate, as a result of stress or pain, reduces GABAergic transmission by engaging mGluR5-mediated endocannabinoid production and presynaptic cannabinoid $\mathrm{CB}_{1}$ receptor activation. 


\section{References}

Arriza JL, Fairman WA, Wadiche JI, Murdoch GH, Kavanaugh MP, Amara SG (1994) Functional comparisons of three glutamate transporter subtypes cloned from human motor cortex. J Neurosci 14:5559-5569.

Azkue JJ, Knöpfel T, Kuhn R, Mateos JM, Grandes P (1997) Distribution of the metabotropic glutamate receptor subtype mGluR5 in rat periaqueductal grey and relationship with ascending spinofugal afferents. Neurosci Lett 228:1-4.

Barbaresi P (2001) Glutamate transporter EAAC1 in the cat periaqueductal gray matter. Neurosci Lett 314:9-12.

Bergles DE, Diamond JS, Jahr CE (1999) Clearance of glutamate inside the synapse and beyond. Curr Opin Neurobiol 9:293-298.

Brasnjo G, Otis TS (2001) Neuronal glutamate transporters control activation of postsynaptic metabotropic glutamate receptors and influence cerebellar long-term depression. Neuron 31:607-616.

Centonze D, Rossi S, Prosperetti C, Gasperi V, De CV, Bari M, Tscherter A, Febbraro F, Bernardi G, Maccarrone M (2007) Endocannabinoids limit metabotropic glutamate 5 receptor-mediated synaptic inhibition of striatal principal neurons. Mol Cell Neurosci 35:302-310.

Costa B, Siniscalco D, Trovato AE, Comelli F, Sotgiu ML, Colleoni M, Maione S, Rossi F, Giagnoni G (2006) AM404, an inhibitor of anandamide uptake, prevents pain behaviour and modulates cytokine and apoptotic pathways in a rat model of neuropathic pain. $\mathrm{Br} \mathrm{J}$ Pharmacol 148:1022-1032.

Danbolt NC (2001) Glutamate uptake. Prog Neurobiol 65:1-105.

de Novellis V, Marabese I, Palazzo E, Rossi F, Berrino L, Rodella L, Bianchi R, Rossi F, Maione S (2003) Group I metabotropic glutamate receptors modulate glutamate and gamma-aminobutyric acid release in the periaqueductal grey of rats. Eur J Neurosci 462:73-81.

Diamond JS (2002) A broad view of glutamate spillover. Nat Neurosci 5:291-292.

Drew GM, Vaughan CW (2004) Multiple metabotropic glutamate receptor subtypes modulate GABAergic neurotransmission in rat periaqueductal grey neurons in vitro. Neuropharmacology 46:927-934.

Fields HL, Basbaum AI, Heinricher MM (2006) Central nervous systems mechanisms of pain modulation. In: Textbook of pain, Ed 5 (McMahon SB, Koltzenburg M, eds), pp 125-142. Philadelphia: Elsevier, Churchill Livingston.

Finn DP, Jhaveri MD, Beckett SR, Roe CH, Kendall DA, Marsden CA, Chapman V (2003) Effects of direct periaqueductal grey administration of a cannabinoid receptor agonist on nociceptive and aversive responses in rats. Neuropharmacology 45:594-604.

Fitzjohn SM, Bortolotto ZA, Palmer MJ, Doherty AJ, Ornstein PL, Schoepp DD, Kingston AE, Lodge D, Collingridge GL (1998) The potent mGlu receptor antagonist LY341495 identifies roles for both cloned and novel mGlu receptors in hippocampal synaptic plasticity. Neuropharmacology 37:1445-1458.

Fitzsimonds RM, Dichter MA (1996) Heterologous modulation of inhibitory synaptic transmission by metabotropic glutamate receptors in cultured hippocampal neurons. J Neurophysiol 75:885-893.

Galante M, Diana MA (2004) Group I metabotropic glutamate receptors inhibit GABA release at interneuron-Purkinje cell synapses through endocannabinoid production. J Neurosci 24:4865-4874.

Grueter BA, Gosnell HB, Olsen CM, Schramm-Sapyta NL, Nekrasova T, Landreth GE, Winder DG (2006) Extracellular-signal regulated kinase 1-dependent metabotropic glutamate receptor 5-induced long-term depression in the bed nucleus of the stria terminalis is disrupted by cocaine administration. J Neurosci 26:3210-3219.

Hohmann AG, Suplita RL, Bolton NM, Neely MH, Fegley D, Mangieri R, Krey JF, Walker JM, Holmes PV, Crystal JD, Duranti A, Tontini A, Mor M, Tarzia G, Piomelli D (2005) An endocannabinoid mechanism for stress-induced analgesia. Nature 435:1108-1112.

Huang H, Bordey A (2004) Glial glutamate transporters limit spillover activation of presynaptic NMDA receptors and influence synaptic inhibition of Purkinje neurons. J Neurosci 24:5659-5669.

Huang YH, Bergles DE (2004) Glutamate transporters bring competition to the synapse. Curr Opin Neurobiol 14:346-352.

Jayamanne A, Greenwood R, Mitchell VA, Aslan S, Piomelli D, Vaughan CW (2006) Actions of the FAAH inhibitor URB597 in neuropathic and inflammatory chronic pain models. Br J Pharmacol 147:281-288.

Jiang L, Xu J, Nedergaard M, Kang J (2001) A kainate receptor increases the efficacy of GABAergic synapses. Neuron 30:503-513.
Jung KM, Mangieri R, Stapleton C, Kim J, Fegley D, Wallace M, Mackie K, Piomelli D (2005) Stimulation of endocannabinoid formation in brain slice cultures through activation of group I metabotropic glutamate receptors. Mol Pharmacol 68:1196-1202.

Kathuria S, Gaetani S, Fegley D, Valino F, Duranti A, Tontini A, Mor M, Tarzia G, La Rana G, Calignano A, Giustino A, Tattoli M, Palmery M, Cuomo V, Piomelli D (2003) Modulation of anxiety through blockade of anandamide hydrolysis. Nat Med 9:76-81.

Keay KA, Bandler R (2001) Parallel circuits mediating distinct emotional coping reactions to different types of stress. Neurosci Biobehav Rev 25:669-678.

La Rana G, Russo R, Campolongo P, Bortolato M, Mangieri RA, Cuomo V, Iacono A, Raso GM, Meli R, Piomelli D, Calignano A (2006) Modulation of neuropathic and inflammatory pain by the endocannabinoid transport inhibitor AM404 [N-(4-hydroxyphenyl)-eicosa-5,8,11,14tetraenamide]. J Pharmacol Exp Ther 317:1365-1371.

Lichtman AH, Cook SA, Martin BR (1996) Investigation of brain sites mediating cannabinoid-induced antinociception in rats: evidence supporting periaqueductal gray involvement. J Pharmacol Exp Ther 276:585-593.

Maejima T, Hashimoto K, Yoshida T, Aiba A, Kano M (2001) Presynaptic inhibition caused by retrograde signal from metabotropic glutamate to cannabinoid receptors. Neuron 31:463-475.

Marcaggi P, Attwell D (2005) Endocannabinoid signaling depends on the spatial pattern of synapse activation. Nat Neurosci 8:776-781.

Martin WJ, Patrick SL, Coffin PO, Tsou K, Walker JM (1995) An examination of the central sites of action of cannabinoid-induced antinociception in the rat. Life Sci 56:2103-2109.

Mathews GC, Diamond JS (2003) Neuronal glutamate uptake contributes to GABA synthesis and inhibitory synaptic strength. J Neurosci 23:2040-2048.

Mitchell SJ, Silver RA (2000) Glutamate spillover suppresses inhibition by activating presynaptic mGluRs. Nature 404:498-502.

Moreira FA, Aguiar DC, Guimaraes FS (2007) Anxiolytic-like effect of cannabinoids injected into the rat dorsolateral periaqueductal gray. Neuropharmacology 52:958-965.

Nieoullon A, Canolle B, Masmejean F, Guillet B, Pisano P, Lortet S (2006) The neuronal excitatory amino acid transporter EAAC1/EAAT3: does it represent a major actor at the brain excitatory synapse? J Neurochem 98:1007-1018.

Ogawa S, Kow LM, Pfaff DW (1994) In vitro electrophysiological characterization of midbrain periaqueductal gray neurons in female rats: responses to GABA- and Met-enkephalin-related agents. Brain Res 666:239-249.

Ohishi H, Akazawa C, Shigemoto R, Nakanishi S, Mizuno N (1995) Distributions of the mRNAs for L-2-amino-4-phosphonobutyrate-sensitive metabotropic glutamate receptors, mGluR4 and mGluR7, in the rat brain. J Comp Neurol 360:555-570.

Ohno-Shosaku T, Shosaku J, Tsubokawa H, Kano M (2002) Cooperative endocannabinoid production by neuronal depolarization and group I metabotropic glutamate receptor activation. Eur J Neurosci 15:953-961.

Palazzo E, Marabese I, de Novellis V, Oliva P, Rossi F, Berrino L, Rossi F, Maione S (2001) Metabotropic and NMDA glutamate receptors participate in the cannabinoid-induced antinociception. Neuropharmacology 40:319-326.

Piet R, Bonhomme R, Theodosis DT, Poulain DA, Oliet SH (2003) Modulation of GABAergic transmission by endogenous glutamate in the rat supraoptic nucleus. Eur J Neurosci 17:1777-1785.

Rothstein JD, Martin L, Levey AI, Dykes-Hoberg M, Jin L, Wu D, Nash N, Kuncl RW (1994) Localization of neuronal and glial glutamate transporters. Neuron 13:713-725.

Sanchez D, Ribas J (1991) Properties and ionic basis of the action potentials in the periaqueductal grey neurones of the guinea-pig. J Physiol (Lond) 440:167-187.

Schindler M, Holloway S, Hathway G, Woolf CJ, Humphrey PP, Emson PC (1998) Identification of somatostatin sst2(a) receptor expressing neurones in central regions involved in nociception. Brain Res 798:25-35.

Semyanov A, Kullmann DM (2000) Modulation of GABAergic signaling among interneurons by metabotropic glutamate receptors. Neuron 25:663-672.

Sepkuty JP, Cohen AS, Eccles C, Rafiq A, Behar K, Ganel R, Coulter DA, Rothstein 
JD (2002) A neuronal glutamate transporter contributes to neurotransmitter GABA synthesis and epilepsy. J Neurosci 22:6372-6379.

Silva E, Hernandez L, Contreras Q, Guerrero F, Alba G (2000) Noxious stimulation increases glutamate and arginine in the periaqueductal gray matter in rats: a microdialysis study. Pain 87:131-135.

Tamaru Y, Nomura S, Mizuno N, Shigemoto R (2001) Distribution of metabotropic glutamate receptor mGluR3 in the mouse CNS: differential location relative to pre- and postsynaptic sites. Neuroscience 106:481-503.

Tsou K, Brown S, Sanudo-Pena MC, Mackie K, Walker JM (1998) Immunohistochemical distribution of cannabinoid $\mathrm{CB1}$ receptors in the rat central nervous system. Neuroscience 83:393-411.

Uchigashima M, Narushima M, Fukaya M, Katona I, Kano M, Watanabe M (2007) Subcellular arrangement of molecules for 2-arachidonoylglycerol-mediated retrograde signaling and its physiological contribution to synaptic modulation in the striatum. J Neurosci 27:3663-3676.

Varma N, Carlson GC, Ledent C, Alger BE (2001) Metabotropic glutamate receptors drive the endocannabinoid system in hippocampus. J Neurosci 21:RC188.

Vaughan CW, Christie MJ (1997) Presynaptic inhibitory action of opioids on synaptic transmission in the rat periaqueductal grey in vitro. J Physiol (Lond) 498:463-472.

Vaughan CW, Connor M, Bagley EE, Christie MJ (2000) Actions of cannabinoids on membrane properties and synaptic transmission in rat periaqueductal gray neurons in vitro. Mol Pharmacol 57:288-295.

Wadiche JI, Jahr CE (2005) Patterned expression of Purkinje cell glutamate transporters controls synaptic plasticity. Nat Neurosci 8:1329-1334.

Walker JM, Huang SM, Strangman NM, Tsou K, Sanudo-Pena MC (1999) Pain modulation by release of the endogenous cannabinoid anandamide. Proc Natl Acad Sci USA 96:12198-12203.

Zhu PJ, Lovinger DM (2005) Retrograde endocannabinoid signaling in a postsynaptic neuron/synaptic bouton preparation from basolateral amygdala. J Neurosci 25:6199-6207. 